\title{
Economic burden and comorbidities of attention-deficit/hyperactivity disorder among pediatric patients hospitalized in the United States
}

\author{
Juliana Meyers ${ }^{1 *}$, Peter Classi $^{2}$, Linda Wietecha ${ }^{3}$, Sean Candrilli ${ }^{4}$
}

\begin{abstract}
Background: This retrospective database analysis used data from the Healthcare Cost and Utilization Project's Nationwide Inpatient Sample (NIS) to examine common primary diagnoses among children and adolescents hospitalized with a secondary diagnosis of attention- deficit/hyperactivity disorder (ADHD) and assessed the burden of ADHD.

Methods: Hospitalized children (aged 6-11 years) and adolescents (aged 12-17 years) with a secondary diagnosis of ADHD were identified. The 10 most common primary diagnoses (using the first 3 digits of the ICD-9-CM code) were reported for each age group. Patients with 1 of these conditions were selected to analyze demographics, length of stay (LOS), and costs. Control patients were selected if they had 1 of the 10 primary diagnoses and no secondary ADHD diagnosis. Patient and hospital characteristics were reported by cohort (i.e., patients with ADHD vs. controls), and LOS and costs were reported by primary diagnosis. Multivariable linear regression analyses were undertaken to adjust LOS and costs based on patient and hospital characteristics.
\end{abstract}

Results: A total of 126,056 children and 204,176 adolescents were identified as having a secondary diagnosis of ADHD. Among children and adolescents with ADHD, the most common diagnoses tended to be mental health related (i.e., affective psychoses, emotional disturbances, conduct disturbances, depressive disorder, or adjustment reaction). Other common diagnoses included general symptoms, asthma (in children only), and acute appendicitis. Among patients with ADHD, a higher percentage were male, white, and covered by Medicaid. LOS and costs were higher among children with ADHD and a primary diagnosis of affective psychoses (by 0.61 days and \$51), adjustment reaction (by 1.71 days and \$940), or depressive disorder (by 0.41 days and \$124) versus controls. LOS and costs were higher among adolescents with ADHD and a primary diagnosis of affective psychoses (by 1.04 days and \$352), depressive disorder (by 0.94 days and \$517), conduct disturbances (by 0.86 days and $\$ 1,330$ ), emotional disturbances (by 1.45 days and $\$ 1,626$ ), adjustment reaction (by 1.25 days and $\$ 702$ ), and neurotic disorders (by 1.60 days and $\$ 541$ ) versus controls.

Conclusion: Clinicians and health care decision makers should be aware of the potential impact of ADHD on hospitalized children and adolescents.

\section{Introduction}

Attention-deficit/hyperactivity disorder (ADHD) is a neurobiological disorder that affects children, adolescents, and adults. It is characterized by a persistent pattern of inattention and/or hyperactivity-impulsivity that is more frequent and severe than typically observed in

\footnotetext{
*Correspondence: jmeyers@rti.org

${ }^{1}$ RTI Health Solutions, 200 Park Offices Drive, Research Triangle Park, NC 27709 USA

Full list of author information is available at the end of the article
}

patients at a comparable stage of development. ADHD has been associated with a wide range of lifelong complications, including academic underachievement, conflicting interactions with peers and family members, and low self-esteem, all of which have far-reaching and longterm consequences for individuals [1]. Furthermore, ADHD is a fairly common disorder, with previous studies estimating the prevalence of ADHD in the United States to be about $9 \%$ in children and $4.4 \%$ in adults $[2,3]$.

\section{Biomed Central}


Patients with ADHD often suffer from comorbid mood and conduct disorders, which may further complicate treatment. Biederman and colleagues estimated that approximately $30 \%$ of pediatric patients with ADHD also had major depression, while Kessler and colleagues found that almost $19 \%$ of adult patients with ADHD also had major depression [4,5]. Previous studies have found that between $4.5 \%$ and $19.4 \%$ of adult patients with ADHD had a concomitant diagnosis of bipolar disorder, compared with about $3.9 \%$ in the general population [4-6]. It has been suggested that oppositional defiant disorder (ODD) has a high rate of overlap with ADHD, with between 35\% and 40\% of ADHD patients also demonstrating signs of ODD [7-10]. Furthermore, patients with ADHD have been found to be at an increased risk of developing substance abuse problems as adults $[11,12]$. In addition, patients with epilepsy and asthma may be at a greater risk of developing ADHD $[13,14]$.

ADHD has been shown to have serious economic implications for children, families, and society. Patients with ADHD often need long-term care, resulting in significant medical expenditures for prescription drugs and psychotherapy. Previous studies have estimated that children with ADHD have annual health care expenditures that are between US \$775 and US \$1,330 greater than children without ADHD [15-17]. It is estimated that adults with ADHD have annual expenditures that are approximately US $\$ 3,000$ greater than adults without ADHD [18].

Despite substantial literature on the costs and economic implications of ADHD, there have been few studies that investigate the impact of ADHD on comorbid conditions and limited studies on the economics of ADHD in the inpatient setting. This study sought to identify the most common primary diagnoses among hospitalized children and adolescents with a secondary diagnosis of ADHD. Patients with these most common primary diagnoses and a secondary diagnosis of ADHD were compared with patients with the same set of primary diagnoses who did not have a secondary ADHD diagnosis to assess differences in patient characteristics, length of hospital stay, and associated costs.

\section{Methods}

Data for this analysis were taken from the Healthcare Cost and Utilization Project (HCUP) Nationwide Inpatient Sample (NIS), a nationally representative inpatient database sponsored by the Agency for Healthcare Research and Quality (AHRQ) [19]. This analysis used data from 2000 to 2006, which represented the most recent years of the NIS available at the time of our study. The NIS is the largest all-payer inpatient care database in the United States and contains data from approximately 8 million hospital stays each year. The data set contains clinical and resource use information typically included in a discharge abstract (e.g., demographics, diagnosis and procedure codes, length of stay [LOS], charges). Financial data in the NIS are presented as charges, which can be converted to costs using facility-specific cost-to-charge ratios. In compliance with the Health Insurance Portability and Accountability Act of 1996 (HIPAA), all data in the database were de-identified to protect the privacy of individual patients, physicians, and hospitals. RTI International's institutional review board determined that this study met all criteria for exemption.

Hospital records for all children (aged 6-11 years) and adolescents (aged 12-17 years) with a secondary diagnosis of ADHD (International Classification of Diseases, 9th Revision, Clinical Modification [ICD-9-CM] codes 314.00 and 314.01) were extracted. The 10 most frequent primary diagnoses, based on the first 3 digits of the ICD-9-CM code, were reported for each age group (Table 1). Pediatric ADHD patients with 1 of the 10 most frequent primary diagnoses were selected for inclusion in the ADHD cohorts (i.e., children with ADHD and adolescents with ADHD). Control cohorts included all children and adolescents with no secondary diagnosis of ADHD who also had 1 of the 10 most frequent primary diagnoses among pediatric ADHD patients.

Study measures for this analysis included patient and hospital characteristics, LOS, and costs. Patient characteristics included patient age, gender, race, primary expected payer (Medicare, Medicaid, private insurance, self-pay, no charge, other, missing), admission source (emergency room, another hospital, another facility, other, missing), admission type (emergency, urgent, elective, newborn, other, missing), discharge disposition (routine, short-term hospital, skilled-nursing facility, intermediate care facility, another facility, home health care, other, died, missing), and year discharged, while hospital characteristics included geographic region (Northeast, Midwest, South, West, missing), location (urban or rural), teaching status, and bed size. LOS and costs were reported by cohort for each primary diagnosis. Costs were converted from charges, using hospitalspecific cost-to-charge ratios, and were updated to 2008 US dollars using the medical care component of the Consumer Price Index.

All data management and analyses were carried out using SAS (version 9.1), Stata (version 11), and SUDAAN (version 9). To account for the complex sampling design of the NIS, appropriate survey-based statistical procedures were employed (i.e., applying sampling weights and using survey procedures to obtain correct variance estimates). Descriptive analyses entailed the 
Table 1 Summary of the 10 Most Common Primary Diagnoses Among ADHD Patientsa

\begin{tabular}{|c|c|c|c|c|c|c|c|c|c|}
\hline \multicolumn{5}{|l|}{ Patients Aged 6-11 Years } & \multicolumn{5}{|l|}{ Patients Aged 12-17 Years } \\
\hline \multirow[b]{2}{*}{ Primary Diagnosis } & \multicolumn{2}{|c|}{$\begin{array}{l}\text { Patients With a } \\
\text { Secondary } \\
\text { ADHD Diagnosis } \\
(\mathrm{n}=126,056)\end{array}$} & \multicolumn{2}{|c|}{$\begin{array}{l}\text { Patients } \\
\text { Without an } \\
\text { ADHD } \\
\text { Diagnosis } \\
\text { (n=2,592,204) }\end{array}$} & \multirow[b]{2}{*}{ Primary Diagnosis } & \multicolumn{2}{|c|}{$\begin{array}{l}\text { Patients With a } \\
\text { Secondary } \\
\text { ADHD Diagnosis } \\
\text { ( } n=204,176)\end{array}$} & \multicolumn{2}{|c|}{$\begin{array}{l}\text { Patients } \\
\text { Without an } \\
\text { ADHD } \\
\text { Diagnosis } \\
\text { (n=5,130,336) }\end{array}$} \\
\hline & $\mathbf{N}$ & $\%$ & $\mathrm{~N}$ & $\%$ & & $\mathrm{~N}$ & $\%$ & $\mathrm{~N}$ & $\%$ \\
\hline 296: Affective psychoses & 30,361 & 24.09 & 37,692 & 0.49 & 296: Affective psychoses & 66,543 & 32.59 & 333,817 & 4.32 \\
\hline 313: Emotional disturbances & 8,297 & 6.58 & 6,584 & 0.09 & 311: Depressive disorder NEC & 10,589 & 5.19 & 68,164 & 0.88 \\
\hline 312: Conduct disturbance NEC & 6,810 & 5.40 & 8,131 & 0.11 & 312: Conduct disturb-ances NEC & 9,906 & 4.85 & 35,254 & 0.46 \\
\hline 780: General symptoms & 6,077 & 4.82 & 85,024 & 1.10 & $\begin{array}{l}\text { 313: Disturb-ances of emotions specific } \\
\text { to childhood and adoles-cence }\end{array}$ & 7,970 & 3.90 & 19,055 & 0.25 \\
\hline 493: Asthma & 5,964 & 4.73 & 262,153 & 3.39 & 309: Adjustment reaction & 7,576 & 3.71 & 49,583 & 0.64 \\
\hline 309: Adjustment reaction & 4,764 & 3.78 & 8,076 & 0.10 & 540: Acute appendicitis & 5,285 & 2.59 & 281,400 & 3.64 \\
\hline 540: Acute appendicitis & 3,892 & 3.09 & 200,290 & 2.59 & 780: General symptoms & 4,662 & 2.28 & 85,565 & 1.11 \\
\hline 311: Depressive disorder NEC & 3,436 & 2.73 & 6,493 & 0.08 & 300: Neurotic disorders & 4,257 & 2.09 & 27,432 & 0.36 \\
\hline 345: Epilepsy & 2,591 & 2.06 & 35,367 & 0.46 & 969: Poisoning by psycho-tropic agents & 3,853 & 1.89 & 29,352 & 0.38 \\
\hline $\begin{array}{l}\text { 486: Pneumonia, } \\
\text { organism NOS }\end{array}$ & 2,245 & 1.78 & 135,420 & 1.75 & 250: Diabetes mellitus & 3,765 & 1.84 & 117,822 & 1.53 \\
\hline
\end{tabular}

$\mathrm{ADHD}=$ attention-deficit/hyperactivity disorder; NEC = Not elsewhere classified; NOS = not otherwise specified.

${ }^{a}$ Patients with a primary ADHD diagnosis were excluded from the analysis.

tabular display of the mean values, medians, ranges, and standard errors (SEs) of continuous variables of interest (age, LOS, costs) and frequency distributions for categorical variables (e.g., race). Students' t-tests and chisquare tests were used to assess the statistical significance of differences across study measures between the study groups.

In addition to descriptive analyses, we conducted multivariable linear regression analyses to estimate the incremental effect of ADHD on LOS and costs. Regressions were estimated for each primary diagnosis within each age group. The use of regression models to analyze cohort differences in LOS and costs allowed us to control for confounding factors that might not otherwise be accounted for (e.g., gender, geographic region).

LOS and cost models were estimated using a generalized linear model (GLM) with a log-link function and a gamma distribution for the error term to resolve the issue of skewed cost and LOS distributions [20,21]. In addition, the GLM method allowed for adjusted, predicted mean LOS and costs of patients in each study group to be directly calculated in the days or dollars scale, thereby avoiding the issue of potentially biased estimates that may result from retransformation of logged coefficients [22].

Each estimated model included a dichotomous indicator variable, equal to 1 if the patient was in the ADHD cohort and equal to 0 if the patient was not in the ADHD cohort, as well as a vector of underlying patient characteristics (i. e., age, gender, race, primary expected payer, geographic region, hospital teaching status, hospital bed size, hospital location, admission source, discharge destination, and year of discharge). Once a regression model was estimated, predicted values were generated for each patient by cohort. Mean adjusted values were reported, with differences in mean predicted values assessed with t-tests.

\section{Results and Discussion \\ Results}

A total of 126,056 children with a secondary diagnosis of ADHD and 204,176 adolescents with a secondary diagnosis of ADHD were identified (Table 1). Among both children and adolescents, the most common primary diagnosis was affective psychoses. Other mental health-related primary diagnoses were common to both age groups (emotional disturbances, conduct disturbances, adjustment reaction, depressive disorder). Additionally, appendicitis and general symptoms were diagnoses common to both cohorts. Among children, diagnoses of asthma, epilepsy, and pneumonia were common, and among adolescents, diagnoses of neurotic disorders, poisoning by psychotropic agents, and diabetes mellitus were common.

Compared with the control cohort, a much higher percentage of patients in the ADHD population were hospitalized with a primary diagnosis of affective disorder $(24.09 \%$ in ADHD children vs. $0.49 \%$ in control children; $32.59 \%$ in ADHD adolescents vs. $4.32 \%$ in control adolescents). This higher rate in the ADHD cohort was found to be true for all mental health-related hospitalizations, including emotional disturbances $16.58 \%$ of ADHD children vs. $0.09 \%$ of control children; $3.90 \%$ of 
ADHD adolescents vs. $0.25 \%$ of control adolescents), conduct disturbances $(5.40 \%$ of ADHD children vs. $0.11 \%$ of control children; $4.85 \%$ of ADHD adolescents vs. $0.46 \%$ of control adolescents), adjustment reaction (3.78\% of ADHD children vs. $0.10 \%$ of control children; $3.71 \%$ of ADHD adolescents vs. $0.64 \%$ of control adolescents), and depressive disorder $(2.73 \%$ of ADHD children vs. $0.08 \%$ of control children; $5.19 \%$ of ADHD adolescents vs. $0.88 \%$ of control adolescents). A similar percentage of patients were hospitalized with appendicitis in both cohorts; however, a much higher percentage of ADHD children and a slightly higher percentage of ADHD adolescents were hospitalized with a diagnosis of general symptoms compared with controls $(4.85 \%$ of ADHD children vs. $1.10 \%$ of control children; $2.28 \%$ of ADHD children vs. $1.11 \%$ of control adolescents). Similarly, a slightly higher percentage of ADHD children had diagnoses of asthma or epilepsy compared with controls (asthma: $4.73 \%$ of ADHD children vs. 3.39\% of control children; epilepsy: $2.06 \%$ of ADHD children vs. $0.46 \%$ of control children). Approximately the same percentages of children in the ADHD and control populations were hospitalized with a primary diagnosis of pneumonia (1.78\% of ADHD children vs. $1.75 \%$ of control children). In adolescents, a slightly higher percentage of patients with ADHD were hospitalized with diagnoses of neurotic disorders or poisoning by psychotropic agents compared with controls (neurotic disorders: $2.09 \%$ of ADHD adolescents vs. $0.36 \%$ of control adolescents; poisoning by psychotropic agents: $1.89 \%$ of ADHD adolescents vs. $0.38 \%$ of controls). A similar percentage of adolescents in both cohorts were hospitalized with a primary diagnosis of diabetes mellitus (1.84\% of ADHD adolescents vs. $1.53 \%$ of control adolescents).

A total of 74,438 children with ADHD and 785,229 children without ADHD had 1 of the 10 most frequent primary diagnoses among ADHD children (Table 2). Children with ADHD were, on average, 6 months older than children without ADHD (mean [SE] 8.74 [0.05] among ADHD children vs. 8.28 [0.02] among control children, $\mathrm{P}<.001)$. When compared with control children, a significantly (significance was defined as $\mathrm{P}<0.05)$ higher percentage of ADHD children were male $(79.10 \%$ of ADHD children vs. $57.50 \%$ of control children, $\mathrm{P}<.001)$, white $(46.01 \%$ of ADHD children vs. $35.05 \%$ of control children, $\mathrm{P}<.001$ ), and covered by Medicaid (58.28\% of ADHD children vs. $40.46 \%$ of control children, $\mathrm{P}<.001)$. Additionally, a significantly smaller percentage of ADHD children were admitted to the hospital from the emergency room compared with control children (38.16\% of ADHD children vs. $59.23 \%$ of control children, $\mathrm{P}<.001)$. In both cohorts, most discharges were labeled as routine (94.14\% of ADHD children vs. $96.48 \%$ of control children), and the highest percentage of patients were from the South $(41.31 \%$ of ADHD children vs. $37.23 \%$ of control children). Additionally, in both cohorts, the majority of children were treated in urban locations (93.58\% of ADHD children vs. $86.82 \%$ of control children) and more than half were treated in teaching hospitals $(61.49 \%$ of ADHD children vs. $56.44 \%$ of control children) and large bed-size hospitals (63.22\% of ADHD children vs. $57.17 \%$ of control children). Furthermore, in both cohorts, the distribution of patients was fairly even across all years of admission.

A total of 124,407 adolescents with ADHD and $1,047,445$ adolescents without ADHD had 1 of the 10 most frequent primary diagnoses among ADHD adolescents. Adolescents with ADHD were on average 6 months younger than adolescents without ADHD (mean [SE] 14.26 [0.04] years among ADHD adolescents vs. 14.72 [0.02] years among control adolescents, $\mathrm{P}<.001$ ). Compared with control adolescents, a significantly higher percentage of ADHD adolescents were male (65.09\% of ADHD adolescents vs. 43.84\% of control adolescents, $\mathrm{P}<.001$ ) or white $(49.99 \%$ of ADHD adolescents vs. $44.91 \%$ of control adolescents, $\mathrm{P}<.001)$. Additionally, a significantly smaller percentage of ADHD children were admitted to the hospital from the emergency room compared with control children (42.41\% of ADHD children vs. $54.47 \%$ of control children $\mathrm{P}=.006)$. Correspondingly, a significantly smaller percentage of ADHD children had their admission type labeled as emergency compared with control children (47.31\% of ADHD children vs. 52.24\% of control children, $\mathrm{P}<.001)$. In both cohorts, most discharges were labeled as routine (90.67\% of ADHD children vs. $92.24 \%$ of control children), and patients were fairly evenly distributed over the 4 geographical regions. Additionally, in both cohorts, the majority of children were treated in urban locations (92.65\% of ADHD children vs. $89.54 \%$ of control children), and more than half were treated in teaching hospitals (54.67\% of ADHD children vs. $52.47 \%$ of control children) and large bed-size hospitals $(66.96 \%$ of ADHD children vs. 63.12\% of control children). Furthermore, in both cohorts, the distribution of patients was fairly even across all years of admission.

Unadjusted LOS was significantly greater (significant defined as $\mathrm{P}<.05$ ) for children with ADHD with a primary diagnosis of adjustment reaction (by 1.71 days, $\mathrm{P}=$ .029) compared to children without ADHD (Table 3). While not statistically significant, unadjusted LOSs tended to be greater for children with ADHD with a primary diagnosis of affective psychoses (by 0.61 days, $\mathrm{P}=.102$ ), emotional disturbances (by 0.08 days, $\mathrm{P}=.928$ ), depressive disorder (by 0.41 days, $\mathrm{P}=.420$ ), and epilepsy (by 0.56 days, $\mathrm{P}=.643$ ) compared to children without ADHD. Similarly, while not statistically significant, unadjusted costs tended to be greater for 
Table 2 Demographic and Hospital Characteristics, by Age Group and Cohort

\begin{tabular}{|c|c|c|c|c|c|c|c|c|c|c|}
\hline & \multicolumn{5}{|c|}{ Patients Aged 6-11 Years } & \multicolumn{5}{|c|}{ Patients Aged 12-17 Years } \\
\hline & \multicolumn{2}{|c|}{$\begin{array}{l}\text { Patients With a } \\
\text { Secondary ADHD } \\
\text { Diagnosis }\end{array}$} & \multicolumn{2}{|c|}{$\begin{array}{l}\text { Patients Without an } \\
\text { ADHD Diagnosis }\end{array}$} & \multirow[b]{2}{*}{$P$ Value } & \multicolumn{2}{|c|}{$\begin{array}{l}\text { Patients With a } \\
\text { Secondary ADHD } \\
\text { Diagnosis }\end{array}$} & \multicolumn{2}{|c|}{$\begin{array}{l}\text { Patients Without an } \\
\text { ADHD Diagnosis }\end{array}$} & \multirow[b]{2}{*}{$P$ Value } \\
\hline & $\mathrm{N}$ & $\%$ & $\mathbf{N}$ & $\%$ & & $\mathrm{~N}$ & $\%$ & $\mathbf{N}$ & $\%$ & \\
\hline Total sample & \multicolumn{2}{|l|}{74,438} & \multicolumn{2}{|l|}{785,229} & & \multicolumn{2}{|l|}{124,407} & \multicolumn{2}{|c|}{$1,047,445$} & \\
\hline \multicolumn{11}{|l|}{ Age } \\
\hline Mean (SE) & 8.74 & 0.05 & 8.28 & 0.02 & $<.001$ & 14.26 & 0.04 & 14.72 & 0.02 & $<.001$ \\
\hline \multicolumn{11}{|l|}{ Gender } \\
\hline Male & 58,883 & 79.10 & 451,525 & 57.50 & $<.001$ & 80,972 & 65.09 & 459,199 & 43.84 & $<.001$ \\
\hline Female & 15,426 & 20.72 & 315,639 & 40.20 & $<.001$ & 43,354 & 34.85 & 580,543 & 55.42 & $<.001$ \\
\hline Missing & 129 & 0.17 & 18,066 & 2.30 & $<.001$ & 81 & 0.06 & 7,703 & 0.74 & $<.001$ \\
\hline \multicolumn{11}{|l|}{ Race } \\
\hline White & 34,246 & 46.01 & 275,189 & 35.05 & $<.001$ & 62,186 & 49.99 & 470,434 & 44.91 & $<.001$ \\
\hline Black & 11,515 & 15.47 & 133,941 & 17.06 & .762 & 12,088 & 9.72 & 110,499 & 10.55 & $<.001$ \\
\hline Hispanic & 5,262 & 7.07 & 130,379 & 16.60 & $<.001$ & 6,124 & 4.92 & 120,415 & 11.50 & $<.001$ \\
\hline Asian or Pacific Islander & 211 & 0.28 & 11,179 & 1.42 & $<.001$ & 333 & 0.27 & 10,477 & 1.00 & $<.001$ \\
\hline Native American & 166 & 0.22 & 3,205 & 0.41 & .030 & 190 & 0.15 & 3,909 & 0.37 & $<.001$ \\
\hline Other & 2,445 & 3.29 & 27,444 & 3.50 & .280 & 3,264 & 2.62 & 29,546 & 2.82 & .137 \\
\hline Missing & 20,593 & 27.66 & 203,892 & 25.97 & .408 & 40,223 & 32.33 & 302,164 & 28.85 & .014 \\
\hline \multicolumn{11}{|c|}{ Primary expected payer } \\
\hline Medicare & 68 & 0.09 & 1,108 & 0.14 & .005 & 217 & 0.17 & 1,785 & 0.17 & .004 \\
\hline Medicaid & 43,379 & 58.28 & 317,705 & 40.46 & $<.001$ & 52,562 & 42.25 & 352,247 & 33.63 & .582 \\
\hline Private Insurance & 26,091 & 35.05 & 399,329 & 50.86 & $<.001$ & 62,702 & 50.40 & 591,369 & 56.46 & .003 \\
\hline Self-pay & 1,377 & 1.85 & 36,973 & 4.71 & $<.001$ & 2,718 & 2.19 & 49,774 & 4.75 & $<.001$ \\
\hline No charge & 90 & 0.12 & 1,787 & 0.23 & .029 & 150 & 0.12 & 2,523 & 0.24 & .001 \\
\hline Other & 3,250 & 4.37 & 26,700 & 3.40 & .202 & 5,597 & 4.50 & 47,095 & 4.50 & .006 \\
\hline Missing & 184 & 0.25 & 1,627 & 0.21 & .556 & 459 & 0.37 & 2,652 & 0.25 & .234 \\
\hline \multicolumn{11}{|l|}{ Admission source } \\
\hline Emergency room & 28,408 & 38.16 & 465,108 & 59.23 & $<.001$ & 52,763 & 42.41 & 570,497 & 54.47 & .006 \\
\hline Another hospital & 3,533 & 4.75 & 32,481 & 4.14 & .004 & 8,057 & 6.48 & 61,063 & 5.83 & $<.001$ \\
\hline Another facility & 1,658 & 2.23 & 7,966 & 1.01 & .002 & 3,164 & 2.54 & 19,516 & 1.86 & $<.001$ \\
\hline Other & 39,427 & 52.97 & 268,892 & 34.24 & $<.001$ & 58,447 & 46.98 & 379,490 & 36.23 & $<.001$ \\
\hline Missing & 1,411 & 1.90 & 10,783 & 1.37 & .213 & 1,975 & 1.59 & 16,879 & 1.61 & .935 \\
\hline \multicolumn{11}{|l|}{ Admission type } \\
\hline Emergency & 32,191 & 43.25 & 409,196 & 52.11 & .803 & 58,861 & 47.31 & 547,153 & 52.24 & $<.001$ \\
\hline Urgent & 24,817 & 33.34 & 171,006 & 21.78 & $<.001$ & 40,116 & 32.25 & 266,490 & 25.44 & .001 \\
\hline Elective & 15,205 & 20.43 & 102,489 & 13.05 & .519 & 20,149 & 16.20 & 129,372 & 12.35 & $<.001$ \\
\hline Newborn & 176 & 0.24 & 938 & 0.12 & .212 & 355 & 0.29 & 1,581 & 0.15 & .170 \\
\hline Other & 5 & 0.01 & 5 & 0.00 & .120 & 283 & 0.23 & 2,342 & 0.22 & .480 \\
\hline Missing & 2,044 & 2.75 & 101,595 & 12.94 & $<.001$ & 4,642 & 3.73 & 100,507 & 9.60 & $<.001$ \\
\hline \multicolumn{11}{|l|}{ Discharge disposition } \\
\hline Routine & 70,073 & 94.14 & 757,615 & 96.48 & .001 & 112,805 & 90.67 & 966,177 & 92.24 & $<.001$ \\
\hline Short-term hospital & 625 & 0.84 & 9,712 & 1.24 & .004 & 1,557 & 1.25 & 12,663 & 1.21 & .625 \\
\hline Skilled-nursing facility & - & - & - & - & - & - & - & - & - & - \\
\hline Intermediate care facility & - & - & - & - & - & - & - & - & - & - \\
\hline Another facility & 2,685 & 3.61 & 6,177 & 0.79 & $<.001$ & 8,287 & 6.66 & 48,417 & 4.62 & $<.001$ \\
\hline Home health care & 303 & 0.41 & 9,458 & 1.20 & $<.001$ & 531 & 0.43 & 9,232 & 0.88 & $<.001$ \\
\hline Other & 500 & 0.67 & 1,434 & 0.18 & $<.001$ & 817 & 0.66 & 8,025 & 0.77 & .001 \\
\hline Died & 9 & 0.01 & 474 & 0.06 & $<.001$ & 10 & 0.01 & 333 & 0.03 & $<.001$ \\
\hline Missing & 243 & 0.33 & 360 & 0.05 & .017 & 399 & 0.32 & 2,597 & 0.25 & .021 \\
\hline
\end{tabular}


Table 2 Demographic and Hospital Characteristics, by Age Group and Cohort (Continued)

\begin{tabular}{|c|c|c|c|c|c|c|c|c|c|c|}
\hline Northeast & 14,964 & 20.10 & 173,830 & 22.14 & .504 & 25,529 & 20.52 & 233,768 & 22.32 & .232 \\
\hline Midwest & 23,426 & 31.47 & 163,678 & 20.84 & $<.001$ & 45,597 & 36.65 & 291,401 & 27.82 & $<.001$ \\
\hline South & 30,752 & 41.31 & 292,322 & 37.23 & .099 & 43,141 & 34.68 & 352,187 & 33.62 & .068 \\
\hline West & 5,296 & 7.11 & 155,398 & 19.79 & $<.001$ & 10,139 & 8.15 & 170,089 & 16.24 & $<.001$ \\
\hline \multicolumn{11}{|l|}{ Location } \\
\hline Rural & 4,755 & 6.39 & 103,181 & 13.14 & .001 & 9,136 & 7.34 & 109,287 & 10.43 & .001 \\
\hline Urban & 69,659 & 93.58 & 681,728 & 86.82 & .001 & 115,262 & 92.65 & 937,891 & 89.54 & .001 \\
\hline Missing & 24 & 0.03 & 320 & 0.04 & .590 & 9 & 0.01 & 267 & 0.03 & $<.001$ \\
\hline \multicolumn{11}{|c|}{ Hospital status } \\
\hline Non-teaching & 28,644 & 38.48 & 341,740 & 43.52 & .835 & 56,389 & 45.33 & 497,552 & 47.50 & .350 \\
\hline Teaching & 45,770 & 61.49 & 443,170 & 56.44 & .832 & 68,009 & 54.67 & 549,626 & 52.47 & .341 \\
\hline Missing & 24 & 0.03 & 320 & 0.04 & .590 & 9 & 0.01 & 267 & 0.03 & $<.001$ \\
\hline \multicolumn{11}{|c|}{ Hospital bed size } \\
\hline Small & 7,762 & 10.43 & 115,576 & 14.72 & .017 & 12,186 & 9.80 & 112,938 & 10.78 & .182 \\
\hline Medium & 19,594 & 26.32 & 220,380 & 28.07 & .307 & 28,910 & 23.24 & 273,046 & 26.07 & .010 \\
\hline Large & 47,058 & 63.22 & 448,953 & 57.17 & .017 & 83,302 & 66.96 & 661,195 & 63.12 & .024 \\
\hline Missing & 24 & 0.03 & 320 & 0.04 & .590 & 9 & 0.01 & 267 & 0.03 & $<.001$ \\
\hline \multicolumn{11}{|c|}{ Year discharged } \\
\hline 2000 & 9,041 & 12.15 & 109,581 & 13.96 & .016 & 13,682 & 11.00 & 149,628 & 14.29 & $<.001$ \\
\hline 2001 & 11,574 & 15.55 & 107,463 & 13.69 & .909 & 17,029 & 13.69 & 160,922 & 15.36 & .278 \\
\hline 2002 & 9,100 & 12.22 & 107,554 & 13.70 & .206 & 14,294 & 11.49 & 137,383 & 13.12 & .041 \\
\hline 2003 & 11,281 & 15.16 & 117,210 & 14.93 & .798 & 22,485 & 18.07 & 163,676 & 15.63 & .065 \\
\hline 2004 & 11,770 & 15.81 & 109,515 & 13.95 & .059 & 19,330 & 15.54 & 152,801 & 14.59 & .095 \\
\hline 2005 & 11,917 & 16.01 & 127,419 & 16.23 & .512 & 19,700 & 15.83 & 149,631 & 14.29 & .103 \\
\hline 2006 & 9,755 & 13.10 & 106,487 & 13.56 & .402 & 17,887 & 14.38 & 133,405 & 12.74 & .022 \\
\hline
\end{tabular}

$\mathrm{ADHD}=$ attention-deficit/hyperactivity disorder; $\mathrm{SE}=$ standard error.

children with ADHD with a primary diagnosis of affective psychoses (by US $\$ 51, \mathrm{P}=.876$ ), adjustment reaction (by US $\$ 940, \mathrm{P}=.245$ ), and depressive disorder (by US $\$ 124, \mathrm{P}=.838$ ) compared to children without ADHD.

Unadjusted LOSs were significantly greater for adolescents with ADHD with a primary diagnosis of affective psychoses (by 1.04 days, $\mathrm{P}<.001$ ), depressive disorder (by 0.94 days, $\mathrm{P}=.005$ ), emotional disturbances (by 1.44 days, $\mathrm{P}=.019$ ), adjustment reaction (by 1.25 days, $\mathrm{P}=$ .002 ), and neurotic disorders (by 1.60 days, $\mathrm{P}=.006$ ). While not statistically significant, unadjusted LOS tended to be greater for adolescents with ADHD with a primary diagnosis of conduct disturbances (by 0.86 days, $\mathrm{P}=.174$ ) compared to adolescents without ADHD. Unadjusted costs were significantly greater for adolescents with ADHD with a primary diagnosis of affective psychoses (by US $\$ 352, \mathrm{P}=.044$ ) and emotional disturbances (by US $\$ 1,626, P=.038$ ). While not statistically significant, unadjusted costs tended to be greater for adolescents with ADHD with a primary diagnosis of depressive disorder (by US $\$ 517, \mathrm{P}=.120$ ), conduct disturbances (by US $\$ 1,330, \mathrm{P}=.154$ ), adjustment reaction (by US $\$ 702, \mathrm{P}=.055$ ), and neurotic disorders (by US
$\$ 541, \mathrm{P}=.135)$ compared to adolescents without ADHD.

Adjusted LOSs were significantly greater for children with ADHD with a primary diagnosis of affective psychoses (by 0.75 days, $\mathrm{P}<.001$ ), adjustment reaction (by 1.96 days, $\mathrm{P}<.001$ ), and epilepsy (by 0.18 days, $\mathrm{P}=$ .021) (Table 4). While not statistically significant, adjusted LOSs tended to be greater for children with ADHD with a primary diagnosis of emotional disturbances (by 0.48 days, $\mathrm{P}=.330$ ) and depressive disorder (by 0.43 days, $\mathrm{P}=.056$ ) compared to children without ADHD. While not statistically significant, adjusted costs tended to be greater for children with ADHD with a primary diagnosis of affective psychoses (by $\$ 216, \mathrm{P}=.397$ ) and adjustment reaction (by $\$ 404, \mathrm{P}=.514$ ) compared to children without ADHD.

Adjusted LOSs were significantly greater for adolescents with ADHD with a primary diagnosis of affective psychoses (by 0.69 days, $\mathrm{P}<.001$ ), depressive disorder (by 0.72 days, $\mathrm{P}<.001$ ), emotional disturbances (by 1.64 days, $\mathrm{P}<.001$ ), adjustment reaction (by 1.23 days, $\mathrm{P}<$ .001 ), and neurotic disorders (by 0.54 days, $\mathrm{P}<.001$ ). While not statistically significant, adjusted LOSs tended to be greater for adolescents with ADHD with a primary diagnosis of conduct disturbances (by 1.64 days, $\mathrm{P}=$ 
Table 3 Length of Stay and Costs, by Cohort, Primary Diagnosis, and Age Group

\begin{tabular}{|c|c|c|c|c|c|c|c|c|c|c|}
\hline \multirow[b]{3}{*}{ Primary Diagnosis } & \multicolumn{9}{|c|}{ Length of Stay } & \multirow{3}{*}{$\begin{array}{r}\text { Costs } \\
P \text { Value }\end{array}$} \\
\hline & \multicolumn{2}{|c|}{$\begin{array}{r}\text { Patients with a } \\
\text { Secondary ADHD } \\
\text { Diagnosis }\end{array}$} & \multicolumn{2}{|c|}{$\begin{array}{r}\text { Patients without } \\
\text { an ADHD } \\
\text { Diagnosis }\end{array}$} & \multirow[t]{2}{*}{$P$ Value } & \multicolumn{2}{|c|}{$\begin{array}{r}\text { Patients with a } \\
\text { Secondary ADHD } \\
\text { Diagnosis }\end{array}$} & \multicolumn{2}{|c|}{$\begin{array}{r}\text { Patients without } \\
\text { an ADHD } \\
\text { Diagnosis }\end{array}$} & \\
\hline & Mean & Std. Error & Mean & Std. Error & & Mean & Std. Error & Mean & Std. Error & \\
\hline \multicolumn{11}{|l|}{ Patients aged 6-11 Years } \\
\hline 296 - Affective psychoses & 9.41 & 0.42 & 8.80 & 0.52 & .102 & $\$ 7,221$ & $\$ 504$ & $\$ 7,170$ & $\$ 578$ & .876 \\
\hline 313 - Emotional disturbances & 10.98 & 0.71 & 10.90 & 0.96 & .928 & $\$ 9,057$ & $\$ 919$ & $\$ 9,479$ & $\$ 948$ & .596 \\
\hline 312 - Conduct disturbance NEC & 11.32 & 0.79 & 11.82 & 1.12 & .543 & $\$ 9,967$ & $\$ 1,232$ & $\$ 10,946$ & $\$ 1,392$ & .185 \\
\hline 780 - General symptoms & 2.17 & 0.06 & 2.33 & 0.06 & .014 & $\$ 4,336$ & $\$ 231$ & $\$ 5,011$ & $\$ 253$ & .008 \\
\hline 493 - Asthma & 2.23 & 0.05 & 2.33 & 0.03 & .006 & $\$ 3,729$ & $\$ 183$ & $\$ 4,182$ & $\$ 152$ & .001 \\
\hline 309 - Adjustment reaction & 11.26 & 1.26 & 9.55 & 0.86 & .029 & $\$ 8,806$ & $\$ 1,513$ & $\$ 7,866$ & $\$ 917$ & .245 \\
\hline 540 - Acute appendicitis & 2.91 & 0.11 & 3.17 & 0.04 & .014 & $\$ 7,417$ & $\$ 248$ & $\$ 8,147$ & $\$ 141$ & .002 \\
\hline 311 - Depressive disorder NEC & 7.80 & 0.59 & 7.39 & 0.42 & .462 & $\$ 6,368$ & $\$ 761$ & $\$ 6,244$ & $\$ 489$ & .838 \\
\hline 345 - Epilepsy & 3.75 & 0.73 & 3.40 & 0.17 & .643 & $\$ 8,847$ & $\$ 1,475$ & $\$ 9,618$ & $\$ 659$ & .607 \\
\hline 486 - Pneumonia, organism NOS & 2.73 & 0.09 & 2.99 & 0.04 & .006 & $\$ 4,273$ & $\$ 216$ & $\$ 5,077$ & $\$ 152$ & .001 \\
\hline \multicolumn{11}{|l|}{ Patients aged 12-17 Years } \\
\hline 296 - Affective psychoses & 8.42 & 0.37 & 7.38 & 0.23 & $<.001$ & $\$ 6,212$ & $\$ 322$ & $\$ 5,859$ & $\$ 274$ & .044 \\
\hline 311 - Depressive disorder NEC & 6.54 & 0.44 & 5.60 & 0.25 & .005 & $\$ 5,379$ & $\$ 500$ & $\$ 4,862$ & $\$ 372$ & .120 \\
\hline 312 - Conduct disturbances NEC & 11.70 & 1.22 & 10.84 & 1.00 & .174 & $\$ 10,874$ & $\$ 2,175$ & $\$ 9,544$ & $\$ 1,361$ & .154 \\
\hline 313 - Emotional disturbances & 9.57 & 0.84 & 8.12 & 0.57 & .019 & $\$ 8,259$ & $\$ 1,268$ & $\$ 6,633$ & $\$ 701$ & .038 \\
\hline 309 - Adjustment reaction & 6.97 & 0.59 & 5.72 & 0.38 & .002 & $\$ 5,371$ & $\$ 589$ & $\$ 4,669$ & $\$ 375$ & .055 \\
\hline 540 - Acute appendicitis & 2.71 & 0.08 & 2.76 & 0.03 & .521 & $\$ 7,954$ & $\$ 217$ & $\$ 8,181$ & $\$ 109$ & .235 \\
\hline 780 - General symptoms & 2.30 & 0.09 & 2.39 & 0.05 & .202 & $\$ 4,894$ & $\$ 253$ & $\$ 5,423$ & $\$ 215$ & .032 \\
\hline 300 - Neurotic disorders & 6.68 & 0.66 & 5.08 & 0.24 & .006 & $\$ 5,323$ & $\$ 455$ & $\$ 4,782$ & $\$ 285$ & .135 \\
\hline 969 - Poisoning by psychotropic agents & 1.62 & 0.08 & 1.62 & 0.03 & .925 & $\$ 3,577$ & $\$ 174$ & $\$ 3,897$ & $\$ 101$ & .088 \\
\hline 250 - Diabetes mellitus & 2.56 & 0.09 & 2.56 & 0.03 & .961 & $\$ 4,177$ & $\$ 198$ & $\$ 4,572$ & $\$ 124$ & .017 \\
\hline
\end{tabular}

$\mathrm{ADHD}=$ attention-deficit/hyperactivity disorder; NEC = Not elsewhere classified; NOS = not otherwise specified; SE = standard error.

.062 ) and diabetes mellitus (by 0.03 days, $\mathrm{P}=.499$ ) compared to adolescents without ADHD. Additionally, while not statistically significant, adjusted costs tended to be greater for adolescents with ADHD with a primary diagnosis of affective psychoses (by $\$ 60, \mathrm{P}=.583$ ), depressive disorder (by $\$ 327, \mathrm{P}=.093$ ), conduct disturbances (by $\$ 986, \mathrm{P}=.133$ ), emotional disturbances (by $\$ 940, \mathrm{P}$ $=.064$ ), and adjustment reaction (by $\$ 213, \mathrm{P}=.404$ ) compared to adolescents without ADHD.

\section{Discussion}

This retrospective database analysis examined demographics, hospital characteristics, LOS, and costs among children and adolescents hospitalized in the United States with a secondary diagnosis of ADHD. The most common primary diagnoses among children and adolescents were identified. Patients with a secondary diagnosis of ADHD were compared with patients without ADHD, using the most commonly observed primary diagnoses. We found that a higher percentage of children and adolescents in the ADHD cohort were male compared with the control cohort and that a lower percentage of children and adolescents in the ADHD group were admitted to the hospital from the emergency room compared with the control cohort. Additionally, a higher percentage of children and adolescents with ADHD had Medicaid listed as their primary expected payer compared with patients without ADHD.

We found that children with ADHD with a primary diagnosis of affective psychoses, adjustment reaction, and depressive disorder had longer LOSs and higher costs compared with children without ADHD. Similarly, adolescents with ADHD with a primary diagnosis of affective psychoses, depressive disorder, conduct disturbances, emotional disturbances, adjustment reaction, and neurotic disorders also had longer LOSs and greater costs compared with adolescents without ADHD. These findings could suggest that children and adolescents with ADHD who are hospitalized for mental disorders may be more difficult to treat compared with children and adolescents without ADHD.

Our study has several limitations common to most retrospective database analyses. First, physician charts were 
Table 4 Adjusted Length of Stay and Costs, by Age and Diagnosis ${ }^{a, b}$

\begin{tabular}{|c|c|c|c|c|c|c|}
\hline & \multicolumn{5}{|c|}{ Length of Stay } & \multirow{2}{*}{$\frac{\text { Costs }}{P \text { Value }}$} \\
\hline & Study Cohort & Control Cohort & $P$ Value & Study Cohort & Control Cohort & \\
\hline \multicolumn{7}{|l|}{ Patients Aged 6-11 Years } \\
\hline 296: Affective psychoses & 9.49 & 8.74 & $<.001$ & 7,547 & 7,331 & .397 \\
\hline 313: Emotional disturbances & 11.95 & 11.47 & .330 & 10,113 & 10,615 & .459 \\
\hline 312: Conduct disturbance NEC & 11.87 & 12.10 & .622 & 10,329 & 11,533 & .036 \\
\hline 780: General symptoms & 2.23 & 2.45 & $<.001$ & 4,617 & 5,255 & $<.001$ \\
\hline 493: Asthma & 2.28 & 2.41 & $<.001$ & 3,979 & 4,393 & $<.001$ \\
\hline 309: Adjustment reaction & 11.29 & 9.33 & $<.001$ & 8,483 & 8,079 & .514 \\
\hline 540: Acute appendicitis & 3.10 & 3.28 & $<.001$ & 7,630 & 8,322 & $<.001$ \\
\hline 311: Depressive disorder NEC & 7.70 & 7.27 & .056 & 6,188 & 6,353 & .534 \\
\hline 345: Epilepsy & 3.82 & 3.64 & .021 & 9,889 & 10,512 & .043 \\
\hline 486: Pneumonia, organism NOS & 2.67 & 3.10 & $<.001$ & 4,387 & 5,442 & $<.001$ \\
\hline \multicolumn{7}{|l|}{ Patients Aged 12-17 Years } \\
\hline 296: Affective psychoses & 8.28 & 7.59 & $<.001$ & $\$ 6,313$ & $\$ 6,253$ & .583 \\
\hline 311: Depressive disorder NEC & 6.57 & 5.85 & $<.001$ & $\$ 5,415$ & $\$ 5,088$ & .093 \\
\hline 312: Conduct disturbances NEC & 12.52 & 11.40 & .062 & $\$ 11,332$ & $\$ 10,346$ & .133 \\
\hline 313: Emotional disturbances & 10.65 & 9.01 & $<.001$ & $\$ 8,725$ & $\$ 7,785$ & .064 \\
\hline 309: Adjustment reaction & 7.13 & 5.90 & $<.001$ & $\$ 5,025$ & $\$ 4,812$ & .404 \\
\hline 540: Acute appendicitis & 2.83 & 2.86 & .375 & $\$ 8,135$ & $\$ 8,323$ & .014 \\
\hline 780: General symptoms & 2.34 & 2.50 & $<.001$ & $\$ 5,016$ & $\$ 5,715$ & $<.001$ \\
\hline 300: Neurotic disorders & 5.75 & 5.21 & $<.001$ & $\$ 4,854$ & $\$ 5,021$ & .383 \\
\hline 969: Poison by psychotropic agents & 1.77 & 1.80 & .082 & $\$ 3,726$ & $\$ 4,105$ & $<.001$ \\
\hline 250: Diabetes mellitus & 2.65 & 2.62 & .499 & $\$ 4,529$ & $\$ 4,899$ & $<.001$ \\
\hline
\end{tabular}

not available to confirm ADHD or other conditions; hospitalizations were identified from diagnosis codes, which, if recorded inaccurately, may cause misidentification of events of interest. Additionally, this study examined only US hospitals; thus, results may not be relevant outside the US setting. Also, only inpatient stays were examined, so results of this analysis may not be generalizable to other care settings.

A number of other studies have used methods similar to those employed in our analysis. Trasande and colleagues studied the burden of obesity on pregnant women and found that obesity was associated with an additional 0.55 inpatient days and an additional US $\$ 1,805$ in costs [23]. In a study looking at LOS and costs among patients with invasive fungal infections versus matched controls, Menzin and colleagues found that patients with fungal infections had significantly longer LOSs and higher costs versus patients without fungal infections (by 11.4 days and by US $\$ 29,281$ ) [24].

\section{Conclusions}

In summary, this study examined common primary diagnoses among children and adolescents with ADHD in an inpatient setting. Patients with a secondary diagnosis of ADHD were compared with patients without ADHD, using the most commonly observed primary diagnoses. Both children and adolescents with ADHD and a primary diagnosis of affective psychoses, adjustment reaction, or depressive disorder had longer LOSs and higher costs compared with patients without ADHD. Additionally, adolescents with ADHD with a primary diagnosis of conduct disturbances, emotional disturbances, and neurotic disorders were found to have longer LOSs and higher costs compared with adolescents without ADHD. Clinicians and other health care decision makers should be aware of the impact that ADHD appears to have on inpatient LOS and costs, when pediatric patients with ADHD present with comorbid conditions in a hospital setting. 


\section{Acknowledgements}

This study was funded by Eli Lilly and Company, Indianapolis, IN, USA. Ms. Meyers and Dr. Candrilli served as contractors for Eli Lilly and are employees of RTI Health Solutions. Ms. Wietecha is a full-time employee of Lilly USA, LLC and a minor shareholder of Lilly. Mr. Classi is a full-time employee and a minor shareholder of Eli Lilly.

\section{Author details}

'RTI Health Solutions, 200 Park Offices Drive, Research Triangle Park, NC 27709 USA. ${ }^{2}$ Eli Lilly and Company, Lilly Corporate Center, DC 6161, Indianapolis, IN 46285 USA. ${ }^{3}$ Lilly USA, LLC, Lilly Corporate Center, DC 6161, Indianapolis, IN 46285 USA. ${ }^{4}$ RTI Health Solutions, 200 Park Offices Drive, Research Triangle Park, NC 27709 USA.

\section{Authors' contributions}

This study was conceived by PC and LW. All authors contributed to the study design and coordination. Database analyses were conducted by SC and JM. The study manuscript was drafted by JM and SC with input from PC and LW. All authors have read and approved the final manuscript.

\section{Competing interests}

This study was funded by Eli Lilly and Company.

Received: 10 September 2010 Accepted: 14 December 2010 Published: 14 December 2010

\section{References}

1. Harpin VA: The effect of ADHD on the life of an individual, their family, and community from preschool to adult life. Arch Dis Child 2005, 90(Suppl 1):i2-i7.

2. Froehlich T, Lanphea B, Epstein J, Barbaresi W, Katusic S, Kahn R: Prevalence, recognition, and treatment of attention-deficit/hyperactivity disorder in a national sample of US children. Arch Pediatr Adolesc Med 2007, 161(9):857-864

3. Secnik K, Spencer T, Ustun T, Walters E, Zaslavsky A: The prevalence and correlates of adult ADHD in the United States: results from the National Comorbidity Survey Replication. Am J Psychiatry 2006, 163:716-723.

4. Biederman J, Faraone S, Milberger S, Curtis S, Chen L, Marrs A, Ouellette C, Moore $\mathrm{P}$, Spencer T: Predictors of persistence and remission of ADHD into adolescence: results from a four year prospective follow-up study. J Am Acad Child Adolesc Psychiatry 1996, 35:343-351.

5. Kessler RC, Adler L, Barkley R, Biederman J, Conners CK, Demler O, Faraone SV, Greenhill LL, Howes MJ, Secnik K, Spencer T, Ustun TB, Walters EE, Zaslavsky AM: The prevalence and correlates of adult ADHD in the United States: results from the national comorbidity survey replication. Am J Psychiatry 2006, 163:716-723.

6. Kessler RC, Berglund P, Demler O, Jin R, Merikangas KR, Walters EE: Lifetime prevalence and age-of-onset distributions of DSM-IV disorders in the national comorbidity survey replication. Arch Gen Psychiatry 2005, 62:593-602.

7. Anderson JC, Williams 5, McGee R, Silva PA: DSM-III disorders in preadolescent children: prevalence in a large sample from the general population. Arch Gen Psychiatry 1987, 44:69-76.

8. Bird HR, Canino G, Rubio-Stipec M, Gould MS, Ribera J, Sesman M, Woodbury M, Huertas-Goldman S, Pagan A, Sanchez-Lacay A, Moscoso M: Estimates of the prevalence of childhood maladjustment in a community survey in Puerto Rico. Arch Gen Psychiatry 1988, 45:1120-1126.

9. Biederman J, Faraone SV, Keenan K, Knee D, Tsuang MT: Family-genetic and psychosocial risk factors in DSM-III attention deficit disorder. J Am Acad Child Adolesc Psychiatry 1990, 29:526-533.

10. Jensen PS, Hinshaw SP, Swanson JM, Greenhill LL, Conners CK, Arnold LE, Abikoff HB, Elliot G, Hechtman L, Hoza B, March JS, Newcorn JH, Severe JB, Vitiello B, Wells K, Wigal T: Findings from the NIMH Multimodal Treatment Study of ADHD (MTA): implications and applications for primary care providers. J Dev and Behav Pediatr 2001, 22(1):60-73.

11. Biederman J, Wilens TE, Mick E, Faraone SV, Spencer T: Does attentiondeficit hyperactivity disorder impact the developmental course of drug and alcohol abuse and dependence? Biol Psychiatry 1998, 44:269-273.

12. Wilens TE, Biederman J, Mick E, Faraone SV, Spencer T: Attention deficit hyperactivity disorder (ADHD) is associated with early onset substance use disorders. J Nerv Ment Dis 1997, 185:475-482.
13. Blackman JA, Gurka MJ: Developmental and behavioral comorbidities of asthma in children. J Dev Behav Pediatr 2007, 28(2):92-99.

14. Dunn DW, Austin JK, Harezlak J, Ambrosius WT: ADHD and epilepsy in childhood. Dev Med Child Neurol 2003, 45:50-54.

15. Guevara J, Lozano P, Wickizer T, Mell L, Gephart H: Utilization and cost of health care services for children with attention-deficit/hyperactivity disorder. Pediatrics 2001, 108(1):71-78.

16. Ray GT, Levine P, Croen LA, Bokhari FAS, Habel LA: Attention-deficit/ hyperactivity disorder in children excess costs before and after initial diagnosis and treatment cost differences by ethnicity. Arch Pediatr Adolesc Med 2006, 160:1063-1069.

17. Swensen AR, Birnbaum HG, Secnik K, Marvnchenko M, Greenberg P, Claxton A: Attention-deficit/hyperactivity disorder: increased costs for patients and their families. J Am Acad Child Adolesc Psychiatry 2003, 42(12): 1415-1423.

18. Secnik K, Swensen A, Lage MJ: Comorbidities and costs of adult patients diagnoses with attention-deficit hyperactivity disorder. Pharmacoeconomics 2005, 23(1):93-102.

19. Steiner C, Elixhauser A, Schnaier J: The Healthcare Cost and Utilization Project: an overview. Eff Clin Pract 2002, 5(3):143-151.

20. Wedderburn RWM: Quasi-likelihood functions, generalized linear models, and the Gauss-Newton method. Biometrika 1974, 61:439-447.

21. Manning WG, Mullahy J: Estimating log models: to transform or not to transform? J Health Econ 2001, 20:461-494.

22. Manning WG: The logged dependent variable, heteroscedasticity, and the retransformation problem. J Health Econ 1998, 17:283-295.

23. Trasande L, Lee M, Liu Y, Weitzman M, Savitz D: Incremental charges, costs, and length of stay associated with obesity as a secondary diagnosis among pregnant.

24. Menzin J, Meyers J, Friedman M, Perfect J, Langston A, Danna R, Papadopoulos G: Mortality, length of hospitalization, and costs associated with invasive fungal infections in high-risk patients. Am J Health Syst Pharm 2009, 66(19):1711-1717.

doi:10.1186/1753-2000-4-31

Cite this article as: Meyers et al:: Economic burden and comorbidities of attention-deficit/hyperactivity disorder among pediatric patients hospitalized in the United States. Child and Adolescent Psychiatry and Mental Health 2010 4:31.

\section{Submit your next manuscript to BioMed Central and take full advantage of:}

- Convenient online submission

- Thorough peer review

- No space constraints or color figure charges

- Immediate publication on acceptance

- Inclusion in PubMed, CAS, Scopus and Google Scholar

- Research which is freely available for redistribution 